Creep Strength of Dispersion Mardened Gold

\begin{tabular}{c|c} 
Temperature & $\begin{array}{c}\text { Stress in } \mathrm{kg} / \mathrm{mm}^{2} \\
\text { for } 100 \text { hour life }\end{array}$ \\
400 & 9.8 \\
500 & 7.0 \\
600 & 6.2 \\
700 & 4.0 \\
800 & 2.8 \\
900 & 1.3 \\
\hline
\end{tabular}

Creep Strength of Pure Gold

395

500

2.60

1.56

When a material is subject to continuous thermal and mechanical stresses at a constant rate, creep occurs which sooner or later leads to fracture. The creep resistance of dispersion hardened gold wires $2 \mathrm{~mm}$ in diameter was determined as an important technical parameter during stress periods of up to 100 hours. These 100 hour values have been compiled over a temperature range from $400^{\circ}$ to $900^{\circ} \mathrm{C}$ and are shown in the table. The equivalent values for gold (9) are included for comparison. The 100 hour creep resistance of dispersion hardened gold at $400^{\circ} \mathrm{C}$ is roughly four times, and at $500^{\circ} \mathrm{C}$ approximately five times, that of gold, and represents a

substantial improvement over dispersion hardening carried out with $\mathrm{Al}_{2} \mathrm{O}_{3}$ or $\mathrm{ThO}_{2}$ (7 and 8).

The specific resistance of dispersion hardened gold is slightly higher-some 10 per cent-than that of pure gold. Determinations on $0.5 \mathrm{~mm}$ diameter wire at $20^{\circ} \mathrm{C}$ gave a figure of $2.44 \mu \mathrm{ohm}-\mathrm{cm}$ for hard drawn wire, and $2.40 \mu \mathrm{ohm}-\mathrm{cm}$ after annealing in air at $800^{\circ} \mathrm{C}$ for 10 hours. These values compare with $2.125 \mu \mathrm{ohm}-\mathrm{cm}$ for pure gold.

Dispersion hardened gold is capable of being brazed. Wires of $1.5 \mathrm{~mm}$ diameter were butt brazed, and tensile tests showed that the strength of the joints was greater than that of the wires in all cases.

Titanium oxide dispersion hardened gold is the subject of a Degussa Patent Application, BRD P2052749 of October $28 \mathrm{th}, 1970$.

\section{References}

1 E. Orowan, Symp. Internal Stresses in Metals and Alloys, Inst. Metals, 1948, 451

2 F. R. N. Nabarro, Proc. Phys. Soc, 1946, 58, 669

3 F. R. N. Nabarro, Adv. Phys., 1952, 1, 269

4 M. F. Ashby, Ph.D. Thesis, Cambridge Univ, 1961 . M. F. Ashby, Phil. Mag., 1966, 14, 1157; R, Ebeling and M. F. Ashby, Phil. Mag., 1966, 13, 805

5 M. Poniatowski and M. Clasing, Z. Metallkunde, 1968 , 59,165

6 Degussa, Patentanmeldung BRD, P 2002886, January 23rd, 1970.

7 N. Fuschillo and M. L. Gimpl, F. Mater. Sci., 1970, 5, 1078

8 M. L. Gimpl and N. Fuschillo, F. Metals, 1971, 23, 39

9 Edelmetall-Taschenbuch, Degussa, 1967

\title{
Structure of Vacuum Evaporated Gold Films
}

\section{SINGLE CRYSTALS PRODUCED BY HEAT TREATMENT}

The vacuum deposition of thin gold films is a widely used process and a considerable amount of research has been devoted to the study of the structure of such films. Special interest has centred on the phenomenon of epitaxy in which a film deposited on a single crystal substrate also exhibits single crystal form in a definite orientation relative to the substrate. It has been shown that for given deposition conditions a certain minimum substrate temperature is required to obtain epitaxial films, although no agreement has been reached on what this temperature is.

The recent work on the vacuum eyaporation of gold on to cleaved rock salt by G. B. Priebsch and W. Fischer at the VEB Keramische Werke at Hermsdorf in East Germany (Hermsdorfer Tech. Mitt., 1971, 32, (11), 1022), has shown that single crystal films can be obtained by the heat treatment of a polycrystalline deposit at $450^{\circ} \mathrm{C}$ in air. The change from a polycrystalline deposit to an orientated deposit was shown by electron diffraction patterns, the Debye-Scherrer rings produced by randomly orientated polycrystalline materials giving place to the spot diffraction pattern obtained from single crystals or a number of crystals in the same orientation. The values of the d-spacings

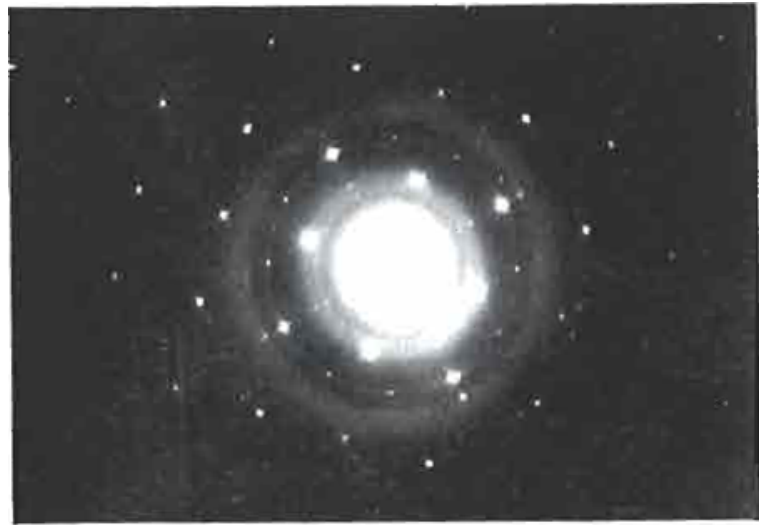

Spot diffraction pattern from orientated crystals after heat treatment of the initial film for 1 hour at $450^{\circ} \mathrm{C}$ in air

for these films are in excellent agreement with those found by Pashley (Phys. Status Solidi, 1965, 10, 153), in his work on the deposition of epitaxial gold films on rock salt.

C. $\mathrm{H}$. 